\title{
Crescimento da Demanda Mundial de Alimentos e Restrições do Fator Terra no Brasil ${ }^{1}$
}

\author{
Kleverton Clovis de Oliveira Saath² e Arlei Luiz Fachinello ${ }^{3}$
}

Resumo: Segundo a FAO (2015), cerca de 805 milhões de pessoas no mundo não têm comida suficiente para levar uma vida saudável e ativa. Também, de acordo com ONU (2012), a população mundial em 2024 será superior a 8 bilhões de pessoas e, em 2050, superior a 9,5 bilhões, exigindo maior oferta de alimentos. O crescimento populacional, o aumento no consumo per capita, na renda per capita e a expansão das cidades nas próximas décadas fazem mais presente o debate sobre a incapacidade de atender às novas necessidades humanas. Pelo lado da oferta, restrições sobre a produtividade ampliam a dimensão do problema. O presente trabalho buscou analisar como o crescimento da demanda mundial de alimentos, no período de 2012 a 2024, deve elevar a demanda por novas terras produtivas no Brasil e as condições para atendê-la. Considerando-se os limites da fronteira agrícola definidos pela Embrapa (2014), conclui-se que, embora exista uma pequena área legalmente disponível para a expansão agropecuária no Brasil, as novas demandas deverão ser atendidas com aumentos de produtividade e/ou substituição de cultura, especialmente sobre a pecuária extensiva. Pequenos ajustes de produtividade regionais e a realocação produtiva serão suficientes para atender às novas demandas no período analisado.

Palavras-chaves: demanda mundial de alimentos, uso da terra, produtividade.

Abstract: According to FAO (2015), roughly 805 million people worldwide do not have enough
food to have healthy and active life. In addition, according to the UN (2012), the world population
in 2024 will exceed 8 billion people and, by 2050, more than 9.5 billion, requiring more food supply.
Population growth, increased per capita consumption, per capita income and expansion of cities in
the coming decades make the debate on the inability to meet the new human needs more present.
Regarding supply, constraints on productivity expand the size of the problem. This study aimed
to analyze how the growing world demand for food, in the period from 2012 to 2024 , may increase
the demand for new farmland in Brazil and the conditions to meet it. Considering the limits of the
agricultural frontier defined by Embrapa (2014), it is concluded that, although there is a small area
legally available for agricultural expansion in Brazil, new demands must be met with increased
1. Data de submissão: 17 de março de 2016. Data de aceite: 17 de setembro de 2017.
2. Universidade Federal de Santa Catarina. Florianópolis-SC, Brasil. E-mail: klevertonsaath1995@
hotmail.com
3. Universidade Federal de Santa Catarina. Florianópolis-SC, Brasil. E-mail: fachinello@hotmail.com 
productivity and/or replacement of culture, especially on extensive livestock farming. Small regional productivity adjustments and production relocation will be sufficient to meet new demands in the analyzed period.

Key-words: global demand for food, land use, productivity.

Classificação JEL: Q11, Q15, Q17, Q18.

DOI: http://dx.doi.org/10.1590/1234-56781806-94790560201

\section{Introdução}

Uma em cada nove pessoas no mundo (ou cerca de 805 milhões de pessoas) não têm comida suficiente para levar uma vida saudável e ativa, de acordo com a FAO (2015). O problema de insegurança alimentar existente hoje é proveniente da impossibilidade das classes mais pobres de terem acesso aos alimentos necessários para uma alimentação saudável e balanceada. As projeções de crescimento populacional, do aumento do consumo per capita, da expansão das cidades e das restrições no uso de terra nas próximas décadas fazem mais presente o debate sobre a incapacidade de atender às necessidades humanas por alimentos.

Com relação à demanda, as projeções populacionais indicam crescimento acelerado e contínuo nas próximas décadas, o que deve elevar a demanda de alimentos em geral. De acordo com a ONU (2012), a população mundial em 2024 será superior a 8 bilhões de pessoas e, em 2050, superior a 9,5 bilhões. Tais números representam crescimento de 13,16\% de 2012 a 2024 e de $34,90 \%$ entre 2012 e 2050 . Este crescimento deve ocorrer principalmente em países em desenvolvimento, mais especificamente na Nigéria, na República Democrática do Congo, na Etiópia e na Índia, onde o número médio de filhos vem crescendo de forma acelerada nos últimos anos (ONU, 2012).

Além da expansão populacional, a concentração nas cidades e o crescimento da renda deve ampliar a demanda de alimentos. A população urbana mundial passou de aproximadamente 746 milhões em 1950 para 3,9 bilhões em 2014. A ONU projeta que o crescimento da população mundial pode trazer mais 2,5 bilhões de pessoas para as áreas urbanizadas até 2050 , com quase 90\% do crescimento centrado na Ásia e na África. Esse processo de urbanização deve ocorrer em conjunto com o crescimento da renda per capita e mudanças no comportamento do consumo da população mundial.

Pelo lado da oferta, a expansão da fronteira agrícola é bastante restrita. Segundo a FAO (2013), a disponibilidade de áreas agrícolas está centrada em poucos países; cerca de $90 \%$ das terras para a expansão agrícola estão na América Latina e África-Subsaariana. Além disso, países como China e EUA não têm mais novas áreas para a exploração agrícola.

Na América Latina, o Brasil se apresenta como um importante produtor mundial de alimentos e com grande potencial de expansão da oferta. Em 2012 foram 246.629 mil hectares na produção agropecuária, sendo $28 \%$ na produção agrícola, $69 \%$ na produção pecuária e 3\% no plantio de floresta. As áreas agricultáveis continuam em expansão, embora em ritmo mais lento; entre 1995 e 2006, houve crescimento de 11,8 milhões de hectares para exploração agropecuária no Brasil, segundo dados do Censo Agropecuário (IBGE, 2015). Mais recentemente, as preocupações ambientais e a preservação das florestas nativas têm levado ao maior controle sobre essa expansão.

Diante das restrições sobre a expansão do uso de terra para uso agropecuário no Brasil, a ampliação da produtividade se apresenta como um caminho necessário para a ampliação da oferta. Segundo FAO (2013), foi exatamente o crescimento da produtividade que permitiu elevar a oferta acima da demanda mundial 
de alimentos no período pós-revolução tecnológica no campo.

Para as próximas décadas, o aumento da produtividade também enfrenta importantes restrições. Segundo FAO (2009), o modelo tecnológico atual está esgotado e observa-se redução nas taxas de crescimento da produtividade das principais lavouras nas últimas décadas. Além disso, Cordell et al. (2009) destacam que agricultura moderna é dependente de fósforo derivado do fosfato de rocha, que é um recurso não renovável, e as reservas globais podem ser esgotadas em 50-100 anos. Outro aspecto importante são as mudanças climáticas. Segundo estudo de Abramovay (2010), verifica-se clara redução na produtividade de algumas culturas quando expostas a temperaturas superiores a $34^{\circ} \mathrm{C}$. IFPRI (2009) fez um estudo com base em diversos modelos climáticos e o resultado reforça a preocupação sobre o declínio geral do crescimento da produtividade agropecuária.

O debate sobre incapacidade de atendimento das demandas futuras de alimentos está sendo retomado por diversos autores, como Abramovay (2010), Da Silveira et al. (1992), Pereira (2010) e Falcon et al. (2005). Dentre os estudos mais recentes, Dobbs et al. (2011) e FAO (2013) analisaram as restrições da fronteira agrícola, mas não abordaram o caso brasileiro. Cordell et al. (2009) e Cordell et al. (2011) analisaram as restrições da produtividade agrícola em relação ao uso de insumos. No entanto, poucos estudos discutem os limites para a expansão agropecuária no Brasil. Isso se deve, em grande parte, ao desconhecimento desse limite. Como destaca Saywer (2013), para alguns pesquisadores a fronteira agrícola brasileira não existe.

Os estudos mais recentes sobre o uso de terras no Brasil em função do crescimento da demanda mundial são apresentados pela Federação das Indústrias do Estado de São Paulo (FIESP, 2014) e pelo Ministério da Agricultura, Pecuária e Abastecimento (MAPA, 2014). Porém, esses dois trabalhos não avançam no debate sobre a exaustão dos recursos naturais, mudanças na produtividade agropecuária e os limites da fronteira agrícola.

Nesse contexto, este trabalho busca analisar como a expansão da demanda mundial de alimentos por produtos brasileiros na próxima década deve elevar as necessidades por novas terras produtivas no País, e quais os avanços, em termos de produtividade, são necessários nas culturas agropecuárias. A hipótese apresentada é que, para o Brasil atender à expansão das demandas por produtos agropecuários até 2024, é necessário expandir a produtividade e áreas plantadas. O estudo utiliza estimativas de crescimento da demanda por exportações e consumo interno do Brasil entre 2012 e 2024 dos principais produtos alimentícios e outros produtos agropecuários (celulose e etanol), relacionando-os à necessidade de produção e terras.

Além desta introdução e problemática, o artigo apresenta, na seção 2 , uma breve revisão teórica, na seção 3, os aspectos metodológicos, seguidos dos resultados e análises na seção 4 . Por fim, são apresentadas algumas conclusões.

\section{Disponibilidade de novas terras agropecuárias no mundo e no Brasil}

Lal (1990) informa que a área terrestre no mundo, adequada para a agricultura, incluindo pecuária, em uso e potencial, compreende cerca de 3 bilhões de hectares. Entretanto, a FAO (2013) constata que, atualmente, mais de 1,5 bilhão de hectares de terras são usadas para a produção agrícola no mundo.

A diferença das terras em uso em relação às terras potenciais constitui a área possível para expansão agrícola mundial. A FAO (2013) mostra que essas áreas estão concentradas em poucos países devido ao processo intenso de expansão agrícola observado em algumas regiões do mundo. O relatório The World Resources Institute (1964) constata que o crescimento da fronteira agropecuária levou a Ásia a cultivar quase 80\% das terras aráveis potenciais. A Fiesp (2014) complementa esta análise ao concluir que, nos EUA, a produção só pode crescer a partir de ganhos restritos de produtividade ou da produção de determinada commodity em detrimento de outra. Essas constatações, dos limites das expansões de novas terras aráveis nos Estados Unidos, também são encontradas no trabalho de Pimentel et al. (1976). Além disso, em conformidade com a FAO (2013), para o sul da Ásia, Ásia Ocidental e África do Norte não há reservas de terras agrícolas. Neste contexto, cerca de $90 \%$ das terras potenciais para expansão agropecuária estão na América Latina e na África Subsaariana, com metade das áreas concentrada em apenas sete países - Brasil, República Democrática do Congo, Angola, Sudão, Argentina, Colômbia e Estado Plurinacional da Bolívia. 
Com base nos dados da Fiesp (2014), percebe-se que o Brasil é fundamental na produção de alimentos, uma vez que é uma das poucas regiões em que ainda é possível aumentar a área agrícola. Além disso, Abramovay (2010) constata que, na África Subsaariana, onde também há terras disponíveis para o crescimento da área agropecuária, devem ocorrer grandes reduções da produção devido ao aquecimento global. Portanto, a produção de alimentos do Brasil para as próximas décadas se torna ainda mais relevante.

Na América Latina, o Brasil se apresenta como grande produtor mundial de alimentos, utilizando extensas áreas de terra para fins produtivos. Contudo, a demanda de novas terras no Brasil também enfrenta os desafios da conversação ambiental. A preocupação com as mudanças climáticas e o assoreamento dos rios levou ao desenvolvimento do Código Florestal Brasileiro (CFB) - Lei Federal no 12.651/2012. Para a Embrapa (2014), a demanda ambiental para a criação de novas Unidades de Conservação, inclusive Áreas de Preservação Permanente (APPs), abrangeria mais de 3 milhões de quilômetros quadrados. Para Daubermann et al. (2014), o crescimento das áreas de preservação ocorre pelo fato de que o mundo vive o dilema do desenvolvimento sustentável, devendo considerar os efeitos do crescimento econômico sobre o meio ambiente. Essa ponderação deve restringir a expansão de novas terras agrícolas nas próximas décadas.

As restrições da expansão da área agropecuária são estudadas pela Embrapa (2014), considerando quatro cenários possíveis. O estudo da Embrapa também é citado nos trabalhos de Miranda et al. (2008), Miranda (2008) e Victória et al. (2008). Segundo Miranda et al. (2008), para analisar o total de área disponível para uso agropecuário no Brasil é necessário quantificar as consequências associadas às diversas restrições de uso e exigências de preservação ambiental.

Na construção da análise da disponibilidade de terras agropecuárias, a Embrapa (2014) não incorpora alterações locais surgidas em 2009, tais como o zoneamento ecológico-econômico da BR 163 e o Código Florestal de Santa Catarina, como áreas de preservação. Por outro lado, são consideradas que as APPs são áreas acima de $1.800 \mathrm{~m}$, declives entre 25 e 45 graus, declives acima de 45 graus e topos de morro. Para o cálculo da Reserva Legal, é considerada a porcentagem de reserva, variando de $80 \%$ no bioma Amazônia a 20\% na Mata Atlântica. Segundo Miranda et al. (2008), a metodologia utilizada para descrever o alcance territorial da legislação ambiental e indigenista foi quantificada com base em dados do Instituto Brasileiro de Meio Ambiente e dos Recursos Naturais Renováveis (Ibama) do Ministério do Meio Ambiente (MMA) e da Fundação Nacional do Índio (Funai). A pesquisa considerou todas as Unidades de Conservação (UCs) federais e estaduais criadas até junho de 2008.

No primeiro cenário, não são consideradas as Áreas de Preservação Permanente (APPs) no cômputo da Reserva Legal. Assim, haveria números negativos no Bioma Amazônia e no Pantanal. Sem computar esses números negativos, a área disponível para a agricultura mais intensiva seria de $2.455 .350 \mathrm{~km}^{2}$, ou cerca de $29 \%$ do território nacional.

Em um cenário posterior, a instituição considera as regras existentes atualmente para inclusão das APPs no cômputo da reserva legal em todo o País. Assim, a disponibilidade das áreas agrícolas cairia para $25,6 \%$ do território nacional. Para Victória (2008), as APPs em topo de morro no Brasil, calculadas a partir do modelo MDE SRTM, com resolução espacial de 90 m, totalizam 398.910 $\mathrm{km}^{2}$. Os estados de Santa Catarina, Espírito Santo, Rio de Janeiro, Minas Gerais e o Distrito Federal apresentaram a maior porcentagem de área de preservação em topo de morro, acima de 10\%. O estado de Minas Gerais apresenta a maior área total $\left(74.000 \mathrm{~km}^{2}\right)$, seguido pelos estados do Pará $\left(51.615 \mathrm{~km}^{2}\right)$ e da Bahia $\left(37.972 \mathrm{~km}^{2}\right)$.

Além desses cenários, o estudo da Embrapa (2014) considera a aplicação da incorporação das APPs no cômputo dos $80 \%$ destinados à reserva legal apenas na Amazônia, a única situação em que é permitida legalmente, e $20 \%$ de Mata Atlântica nas outras regiões. Dessa forma, a disponibilidade total de terras para a agropecuária seria de $2.543 .981 \mathrm{~km}^{2}$ ou cerca de $30 \%$ do território nacional. Esse resultado é utilizado como referência para este artigo, uma vez que este cenário considera as áreas legalmente disponíveis para a agropecuária cumprindo as exigências legais impostas no Código Florestal Brasileiro.

No último cenário, o estudo considera a aplicação da incorporação das APPs no cômputo dos $80 \%$ destinados à reserva legal para todo o País, o que não está previsto no Código Florestal Brasileiro. Assim, a disponibilidade de terras para a agropecuária seria de $3.534 .992 \mathrm{~km}^{2}$, representando $41 \%$ do território nacional. Esse acréscimo de cerca de $1.000 .000 \mathrm{~km}^{2}$ ocorreria fora da Amazônia, já que lá a regra já é válida. 
Após quantificar as áreas em potencial para a agropecuária no Brasil é necessário analisar qual o uso atual pela agropecuária brasileira. De acordo com Helfand et al. (2015), a área total dos estabelecimentos agropecuários no Brasil em 2006 foi de 333,69 milhões de hectares. Conforme o IBGE (2015), pelo Censo Agropecuário de 2006, as áreas das lavouras corresponderam a 59,847 milhões de hectares, matas e florestas plantadas, a 4,5 milhões de hectares e pastagens, a 172,333 milhões de hectares. Totalizando área de 246,63 milhões de hectares, a diferença entre esse total e o total agropecuário é definida como outros usos, tais como áreas improdutivas, benfeitorias, estradas, matas nativas, entre outros.

Ferreira Filho et al. (2012) esclarecem que a fronteira agrícola brasileira está localizada principalmente em Mato Grosso, Rondônia e Pará, estados sobre o chamado "arco do desmatamento". Para De Lima Filho et al. (2013), a produção agropecuária expandiu-se para uma região conhecida como Mapitoba. "Mapitoba" é o acrônimo referente às áreas de chapada dos estados do Maranhão, Piauí, Tocantins e Bahia, de elevada aptidão agrícola e que, até recentemente, ainda se encontravam brutas, cobertas por Cerrado. Para os autores, essa região é a última fronteira agropecuária do Brasil.

Diante da limitação de terras disponíveis para a agricultura e pecuária no Brasil, Carvalho (2010), Oliveira (2010) e Brasil (2015) afirmam que a ampliação da produtividade é o caminho alternativo para a ampliação da oferta. Segundo estudos da FAO de 2009 e 2013, foi exatamente o crescimento da produtividade que permitiu elevar a oferta acima da demanda mundial de alimentos no período pós-revolução tecnológica no campo. A Revolução Verde dos anos 1960 também marcou uma nova era para o crescimento da oferta via ampliação da produtividade.

Ainda, segundo Ferreira Filho et al. (2012), a necessidade de reduzir a expansão da agropecuária sobre as matas naturais transforma a produção extensiva em intensiva e realoca as culturas. Para os autores, observa-se grande potencial de expansão na margem intensiva em estados como São Paulo e Santa Catarina (com o Rio Grande do Sul). Por outro lado, o Paraná tem a menor percentagem, sugerindo que, para este estado, as possibilidades de expansão agrícola na margem intensiva são mais restritas.

\section{Metodologia}

\subsection{Matriz de insumo-produto}

Para a análise dos impactos da demanda mundial de alimentos no período de 2012 a 2024 sobre a produção e o uso das áreas de terras no Brasil foi utilizado o instrumental de insumo-produto, que permitiu relacionar as novas demandas por produtos processados com a produção agropecuária e suas respectivas demandas por áreas de terra. O modelo de insumo-produto é um instrumento que permite a análise de impactos de variações na demanda sobre a produção e diversas outras variáveis relacionadas. Nele, a economia funciona como uma vasta rede tentando equacionar oferta e demanda. Entre as referências para esse tipo de método, foram utilizados os textos de Miller e Blair (2010) e Bulmer-Thomas (1982).

$\mathrm{O}$ modelo de insumo-produto pode ser apresentado da seguinte forma:

$$
\sum_{j=1}^{n} a_{i j} x_{j}+y_{i}=x_{i} \quad \forall i=1,2,3, \ldots, n
$$

Em que $a_{i j}$ denota o coeficiente técnico de uso de insumos do setor $i$ que é necessária para a produção de uma unidade de produto final do setor $j, x_{j}$ é o produto do setor $j, y_{i}$ é a demanda final por produtos do setor $i$ e $x_{i}$ é o total do produto $i$. Essa equação representa o produto total, sendo a soma das demandas para consumo intermediário e final. Pode-se representar essa igualdade no formato matricial, como segue:

$$
A x+y=x
$$

rearranjando os termos, tem-se o modelo analítico de insumo-produto:

$$
x(I-A)=y \quad \text { ou } \quad x=(I-A)^{-1} y
$$

pode-se ainda representar a relação entre os vetores de demanda e de produção em variação:

$$
\Delta \text { Área }=\Delta X=(I-A)^{-1} \Delta Y
$$

Assim, o impacto total sobre a produção de uma variação na demanda final é resultado de um ciclo de ajuste produtivo nos diversos setores econômicos. Tomando-se como base coeficientes fixos entre produto e área de terra, num primeiro momento, têm-se variações de área de terra igual às variações da produção. Isso reflete a hipótese de produtividade constante. 
Foram também avaliadas as possibilidades de mudança nas produtividades dos produtos agropecuários e o grau de ajustes necessário para o atendimento das novas demandas, utilizando as projeções de área total disponível para a produção agropecuária.

A matriz insumo-produto utilizada tem como base 2012. Ela foi elaborada a partir das Contas Nacionais do Brasil. Tendo como base as Tabelas de Recursos e Usos das Contas Nacionais do Brasil, divulgadas por IBGE (2015a), a matriz de insumo-produto a preço básico foi construída, baseada nos procedimentos apresentados em Guilhoto e Sesso-Filho (2010).

\subsection{Fontes dos dados}

Para a implementação do modelo, possíveis crescimentos na demanda por alimentos no Brasil e no mundo entre 2012 e 2024 foram avaliados. Esses números resultam de diversas estimativas divulgadas da Fiesp (2014) e MAPA (2014).

As variações de ovos, algodão, café, etanol e suco de laranja correspondem às projeções da Fiesp (2014); os dados do consumo de carne bovina, carne de frango, carne suína, leite, açúcar, arroz, celulose, feijão, milho, óleo de soja, soja, trigo, papel e fumo correspondem às projeções do Mapa (2014).

Para produção e produtividade dos principais produtos da lavoura são analisados os dados da Produção Agrícola Municipal (PAM), do IBGE. Já para o uso das terras pela agropecuária são utilizados os dados dos Censos Agropecuários e da Pesquisa Agrícola Municipal (IBGE, 2015b). Para a produtividade da silvicultura é utilizada a produção de lenha e tora da Pesquisa Produção da Extração Vegetal e da Silvicultura e área de florestas plantadas disponibilizada pelo IBGE (2015b). Para 2012 é utilizada a produção de lenha e tora do IBGE (2015) e áreas plantadas no Anuário da Silvicultura em 2012, conforme Santos et al. (2012). Para a produtividade da pecuária em 2024 utilizou-se a lotação proposta por Carvalho et al. (2010). Para a silvicultura foi mantida a taxa de 2012.

Os dados da lotação da pecuária de 1970 a 2006 são obtidos pela razão do rebanho efetivo pela soma das áreas de pastagens naturais e plantadas, disponibilizada nos Censos Agropecuários 1970/2006 em IBGE (2015). Para 2012 é utilizado o rebanho efetivo de bovinos disponibilizado pela Pesquisa Pecuária Municipal do IBGE, e os dados de área de pastagem correspon- dem ao trabalho Anuário da Pecuária 2013 (POLL et al., 2013).

Os dados da disponibilidade de terras para uso agropecuário e as áreas de preservação são do estudo da Embrapa (2014).

\section{Crescimento da demanda mundial por alimentos e a disponibilidade de novas áreas de terra para fins agropecuários no Brasil}

A terra é um fator básico para a produção de alimentos e, historicamente, a expansão agrícola veio acompanhada da incorporação de novas áreas de terra. Mais recentemente, as mudanças no clima e as preocupações com a manutenção das áreas de floresta nativa expõem com mais clareza os limites dessa expansão. Muitas regiões do mundo, já sem possibilidade de expansão de área, dependem somente de aumentos de produtividade para atender às novas demandas. Segundo a FAO (2013), o Brasil é um dos principais países com terras aráveis disponíveis, o que deve ampliar ainda mais seu papel como importante fornecedor mundial de alimentos.

Para analisar como as futuras demandas mundiais de alimentos por produtos brasileiros devem pressionar o uso da terra no Brasil, inicialmente são apresentados na Tabela 1 os níveis de demanda por exportações e demanda doméstica de 2012, as respectivas taxas de crescimento projetadas entre 2012 e 2024 e as variações percentuais de produção que seriam necessárias para atender às novas demandas. Para essa avaliação inicial, a produtividade foi mantida constante, de forma que se possa compreender um possível crescimento da demanda por novas áreas de terras nesse período. $\mathrm{Na}$ sequência, ajustes de produtividade serão avaliados.

Com relação aos produtos da pecuária, as mudanças na estrutura demográfica mundial devem elevar a participação das proteínas ${ }^{4}$ na dieta alimentar, proporcionando o crescimento da demanda por carnes (FAO, 2009). Para a carne bovina, as projeções de crescimento das exportações são de cerca de $40 \%$ e, para o consumo doméstico, em torno de $16 \%$ entre 2012 e 2024, o que deve resultar em expansão de $12,6 \%$ no volume

4. O consumo de carne per capita passaria de $41 \mathrm{~kg}$, em 2009, para $52 \mathrm{~kg}$ em 2050 (de 30 para $44 \mathrm{~kg}$ nos países em desenvolvimento) (FAO, 2009, p. 11). 
produzido no Brasil no período. Segundo a Fiesp (2014), a redução da produção dos principais países concorrentes também traz oportunidades de expansão das exportações de carne bovina brasileira nos próximos anos. A expansão de $12,6 \%$ da produção de carne bovina no Brasil exigiria crescimento de $4,8 \%$ no rebanho do País.

A demanda projetada por carnes suína e de aves também apresenta taxas elevadas de expansão nas exportações e no consumo doméstico: crescimentos de $15,3 \%$ e $19,4 \%$, respectivamente. A abertura de novos mercados, junto à persistência de problemas sanitários em outros países tende a impulsionar a demanda mundial pelas carnes do Brasil. Embora a produção desses animais seja intensiva e concentrada em pequenas áreas de terra, o crescimento da produção deve elevar a demanda de grãos para a alimentação animal.
O milho e a soja são os principais insumos na produção de rações. Para o milho, os números apresentados na Tabela 1 indicam crescimento de $4,1 \%$ do volume entre 2012 e 2024, impulsionado também pela demanda externa. Para esses dois produtos a previsão é de contínuo crescimento das exportações, sendo de $60,5 \%$ e $44,0 \%$ no período, respectivamente. Para atender às demandas estimadas, o volume de soja produzido no Brasil precisa crescer 2,6\%, o que exigiria uma grande expansão de área, considerando-se a produtividade constante.

A cana-de-açúcar e o algodão também são atividades que atualmente ocuparam grandes áreas de terra no Brasil e as estimativas indicam crescimento no período avaliado. Estima-se expansão de $42,3 \%$ das exportações e $24,2 \%$ do consumo doméstico de açúcar, assim como 1,8\% e 78,6\% para as demandas de etanol,

Tabela 1. Crescimento da demanda e da produção de produtos agropecuários brasileiros entre 2012 e 2024

\begin{tabular}{|c|c|c|c|c|c|c|}
\hline & Produtos & $\begin{array}{c}\text { Exportações } \\
\text { em } 2012 \\
\text { (R\$ milhões) } \\
\end{array}$ & $\begin{array}{c}\text { Variação } \\
\text { exportações } \\
(\%) \\
\end{array}$ & $\begin{array}{c}\text { Demanda } \\
\text { doméstica 2012 } \\
\text { (R\$ milhões) } \\
\end{array}$ & $\begin{array}{c}\text { Variações } \\
\text { Dem. doméstica } \\
(\%)\end{array}$ & $\begin{array}{c}\text { Var. da } \\
\text { Produção } \\
(\%) \\
\end{array}$ \\
\hline \multirow{14}{*}{ 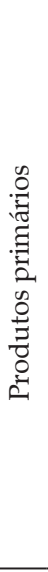 } & Arroz e trigo & 3.128 & - & 276 & - & 1,34 \\
\hline & Milho & 4.153 & 60,47 & 4.389 & - & 4,10 \\
\hline & Algodão & 4.657 & 138,61 & 8 & - & 18,66 \\
\hline & Cana-de-açúcar & - & - & 1.437 & - & 5,07 \\
\hline & Soja & 31.173 & 44,04 & 50 & - & 2,64 \\
\hline & Outros produtos (L.T) & 521 & - & 20.606 & - & 1,02 \\
\hline & Laranja & 20 & - & 1.194 & - & 2,42 \\
\hline & Café em grão & 18.285 & $-4,39$ & 460 & - & $-0,31$ \\
\hline & Outros produtos (L.P) & 609 & - & 8.407 & - & 0,70 \\
\hline & Bovinocultura & 627 & - & 576 & - & 4,80 \\
\hline & Leite de vaca & - & - & 6.302 & 27,29 & 8,68 \\
\hline & Suínos & 42 & - & 166 & - & 5,17 \\
\hline & Aves e ovos & 261 & 29,16 & 4.470 & 34,80 & 8,21 \\
\hline & Produtos da silvicultura & 470 & - & 4.774 & - & 0,44 \\
\hline \multirow{14}{*}{ 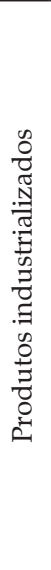 } & Carne de bovinos & 8.817 & 39,70 & 44.052 & 15,61 & 12,61 \\
\hline & Carne suína & 1.687 & 46,82 & 4.057 & 29,12 & 15,33 \\
\hline & Carne de aves & 12.615 & 44,53 & 14.516 & 33,05 & 19,43 \\
\hline & Leite resfriado & - & 34,06 & 918 & 27,29 & 10,05 \\
\hline & Açúcar & 20.316 & 42,89 & 5.529 & 24,19 & 16,53 \\
\hline & Conservas e sucos de frutas & 4.216 & 16,91 & 21.690 & 47,22 & 21,40 \\
\hline & Óleos vegetais & 12.959 & 18,34 & 6.690 & 23,13 & 7,01 \\
\hline & Café beneficiado & 912 & $-4,39$ & 6.068 & 24,92 & 9,13 \\
\hline & Produtos do arroz & 1.770 & - & 5.645 & 1,96 & 1,50 \\
\hline & Produtos do trigo & 196 & - & 9.967 & 17,44 & 1,38 \\
\hline & Produtos do fumo & 3.163 & 22,54 & 3.946 & 22,54 & 23,63 \\
\hline & Celulose & 6.690 & 39,42 & - & 18,16 & 5,56 \\
\hline & Papel & 2.391 & 20,39 & 4.982 & 24,49 & 0,60 \\
\hline & Etanol & 2.648 & 1,80 & 233 & 78,58 & 3,10 \\
\hline
\end{tabular}

Fonte: Mapa (2014), Fiesp (2014), IBGE (2015) e resultados do modelo. Elaboração própria. 
respectivamente. Isso deve elevar a demanda por cana-de-açúcar em 5,1\%. Já para o algodão, o crescimento de suas exportações acima de $100 \%$ e do setor têxtil nacional explicam a projeção de expansão de $18,7 \%$ da produção nacional entre 2012 e 2024. Os óleos vegetais representam uma alternativa aos derivados de petróleo, o que deve contribuir para elevar a demanda por oleaginosas e cana-de-açúcar, segundo Ferrari (2005).

No segmento de Exploração Florestal, mesmo diante da tendência de queda dos preços e do aumento da oferta mundial da celulose, os planos de investimento no setor continuam para os próximos anos no Brasil (FIESP, 2014). Estima-se expansão de 0,44\% na produção, resultado, em grande parte, do aumento estimado de 5,56\% na demanda final de celulose, respectivamente. Segundo o Mapa (2014), o crescimento estimado das exportações de celulose entre 2012 e 2024 é de 39,42\%. Essas atividades utilizaram grandes áreas de terra no Brasil e a tendência é continuar aumentando.

Na Tabela 2 são visualizadas as áreas utilizadas pelas principais atividades agropecuárias em 2012, as variações de área esperadas e o total que seria necessário em 2024 para atender às novas demandas, assim como as variações e participações nesse período.
Mantidos os níveis de produtividade de 2012, projeta-se crescimento de 10,5 milhões de hectares de áreas para a área agropecuária até 2024, especialmente para a produção de alimentos. Isso representa acréscimo de 4,27\% na área explorada em 2012 no Brasil. É importante observar que não estão sendo considerados aspectos de redistribuição produtiva nesse estudo, embora seja uma proposta para um estudo futuro.

Mantidas as produtividades, a pecuária é a atividade que mais demandará novas áreas de terras no Brasil; são 8,2 milhões de hectares a mais, ou cerca de $80 \%$ das novas áreas demandadas. Segundo dados disponibilizados por Poll et al., (2013), em 2012 o setor ocupou 171 milhões de hectares. Considerando-se a mesma lotação para 2024, as estimativas realizadas indicam a utilização de 179,297 milhões de hectares, o que representa $69,7 \%$ da área utilizada pelas atividades agropecuárias. Entre as áreas utilizadas pelas atividades apresentadas na Tabela 2, além da bovino-cultura, destacam-se a soja, o milho e a cana-de-açúcar. Somente essas atividades ocuparam cerca de $90 \%$ das áreas produtivas do País. Também são elas que irão demandar a maior parcela das novas terras. Incluindo a produção de algodão, o grupo é responsável por 97,3\% da demanda de novas terras para uso agropecuário.

Tabela 2. Áreas de terras em uso em 2012 e necessárias em 2024 no Brasil com produtividade constante (mil ha)

\begin{tabular}{|c|c|c|c|c|c|c|}
\hline Produtos & $\begin{array}{l}\text { Áreas utilizadas } \\
\text { em } 2012\end{array}$ & $\begin{array}{l}\text { Partic. } \\
\% 2012\end{array}$ & $\begin{array}{c}\text { Variação } \\
\text { \% de área estimada }\end{array}$ & $\begin{array}{l}\text { Var. Área } \\
\text { (mil ha) }\end{array}$ & $\begin{array}{l}\text { Áreas necessárias } \\
\text { em } 2024 \text { (mil ha) }\end{array}$ & $\begin{array}{l}\text { Par.\% } \\
2024\end{array}$ \\
\hline Arroz & 2.443 & 0,99 & 1,34 & 33 & 2.476 & 0,96 \\
\hline Trigo & 1.942 & 0,79 & 1,34 & 26 & 1.968 & 0,77 \\
\hline Milho em grão & 15.065 & 6,11 & 4,10 & 617 & 15.683 & 6,10 \\
\hline Algodão herbáceo & 1.433 & 0,58 & 18,66 & 267 & 1.700 & 0,66 \\
\hline Cana-de-açúcar & 9.752 & 3,95 & 5,07 & 495 & 10.247 & 3,98 \\
\hline Soja em grão & 25.091 & 10,17 & 2,64 & 663 & 25.754 & 10,01 \\
\hline Feijão & 3.183 & 1,29 & 1,02 & 32 & 3.215 & 1,25 \\
\hline Mandioca & 1.758 & 0,71 & 1,02 & 18 & 1.776 & 0,69 \\
\hline Outros produtos (L.T) & 1.928 & 0,78 & 1,02 & 20 & 1.948 & 0,76 \\
\hline Laranja & 730 & 0,30 & 2,42 & 18 & 747 & 0,29 \\
\hline Café em grão & 2.120 & 0,86 & $-0,31$ & -7 & 2.114 & 0,82 \\
\hline Coco-da-baía & 258 & 0,10 & 0,70 & 2 & 260 & 0,10 \\
\hline Banana & 481 & 0,20 & 0,70 & 3 & 484 & 0,19 \\
\hline Dendê & 113 & 0,05 & 0,70 & 1 & 114 & 0,04 \\
\hline Outros produtos (L.P) & 2.406 & 0,98 & 0,70 & 17 & 2.423 & 0,94 \\
\hline Bovinos & 171.000 & 69,33 & 4,80 & 8.207 & 179.207 & 69,69 \\
\hline Produtos da silvicultura & 6.516 & 2,64 & 0,44 & 29 & 6.545 & 2,54 \\
\hline Produtos do fumo & 411 & 0,17 & 23,63 & 97 & 508 & 0,20 \\
\hline Total & 246.629 & 100 & 4,27 & 10.538 & 257.166 & 100 \\
\hline
\end{tabular}

Fonte: Áreas plantadas para 2012, IBGE (2015b), áreas da silvicultura, Santos et al. (2012), áreas da bovinocultura, Poll et al. (2013) e resultados do modelo. Elaboração própria. 
O café é a única atividade produtiva em que as estimativas indicam o recuo de produção e área. Segundo a Fiesp (2014), produtores de café estão enfrentando um forte surto de ferrugem e as indicações são que esse processo deverá levar alguns anos, dada a descapitalização dos cafeicultores e, em muitos casos, a necessidade de replantio das lavouras e suas substituições por variedades mais resistentes.

O crescimento da demanda mundial por alimentos do Brasil deverá exigir novas áreas produtivas, de acordo com os limites e condições agora impostas. Entre os principais condicionantes, podem ser destacadas as mudanças climáticas e as novas exigências legais. Em 2014, a Empresa Brasileira de Pesquisa Agropecuária (Embrapa) estimou em 254,4 milhões de hectares o limite legal de área para fins agropecuários no Brasil (EMBRAPA, 2014). Essa disponibilidade legal para a agropecuária considera apenas as regras de inclusão nas Áreas de Preservação Permanente (APPs), no cômputo da reserva legal, existente para a Amazônia.

O estudo não incorpora as alterações locais, surgidas em 2009, como o zoneamento ecológico-econômico da BR 163 e o Código Florestal de Santa Catarina, na estimativa de área legalmente disponível, segundo a Embrapa (2014).

Na Tabela 3 são apresentadas estatísticas de uso de áreas entre 1970 e 2006, assim como estimativas de uso e da fronteira legal disponível, realizadas pelos autores. Embora o interesse seja em dados mais recentes, foram apresentados os dados desde a década de 1980 para fins de comparação. O cálculo da fronteira agropecuária brasileira, realizada pelos autores, considera a diferença entre as terras utilizadas no ano corrente e a disponibilidade legal para a agropecuária estimada pela Embrapa. Para 2006, esse cálculo indica disponibilidade de 31,3 milhões de hectares e, em 2012, 7,7 milhões.

As áreas de lavouras, matas e pastagens de 2012 foram estimadas como base na evolução da produção agropecuária, da silvicultura e de projeções realizadas por outras instituições. No caso da evolução da pastagem, utilizou-se a estimativa do Anuário da Pecuária 2013 (POLL et al., 2013). Em 2024, os números refletem as projeções de crescimento apresentadas anteriormente. Na Tabela 3, observa-se redução da disponibilidade de novas áreas de terras entre 2006 e 2012, passando de 31,3 milhões para 7,8 milhões de hectares em 2012. Esse crescimento ocorreu, em grande parte, pela expansão das lavouras, especialmente da produção de soja.

Utilizando-se as estimativas de crescimento da produção de alimentos para 2024, apresentadas anteriormente, verifica-se, na Tabela 3, uma expansão de 3,3\% da área utilizada pelas lavouras e de $4,8 \%$ da área utilizada pela pecuária. Esse padrão de expansão das atividades agropecuárias, mantidas as produtividades de 2012, deve superar em 2,7 milhões de hectares a disponibilidade legal das áreas estimada pela Embrapa (2014).

Nesse caso hipotético, verifica-se a incapacidade de a estrutura produtiva nacional atender às novas demandas mundiais de alimentos. $\mathrm{O}$ desenvolvimento e implantação de novas tecnologias e o crescimento da agricultura em detrimento da lotação na pecuária surgem como soluções necessárias, caso sejam respeitados os limites legais. Esse é o foco da análise do próximo tópico.

Tabela 3. Usos e limites de terras no Brasil para fins agropecuários - 1970/2006 (mil ha)

\begin{tabular}{lcccccc}
\hline & $\mathbf{1 9 8 0}$ & $\mathbf{1 9 8 5}$ & $\mathbf{1 9 9 6}$ & $\mathbf{2 0 0 6}$ & $\mathrm{E}[\mathbf{2 0 1 2}]$ & $\mathrm{E}[\mathbf{2 0 2 4}]$ \\
\hline Lavouras & 49.104 & 52.148 & 41.794 & 59.847 & 69.113 & 71.415 \\
Matas naturais & 83.152 & 83.017 & 88.898 & 93.982 & 93.982 & 93.982 \\
Mata plantada & 5.016 & 5.967 & 5.396 & 4.497 & 6.516 & 6.545 \\
Pastagens & 174.500 & 179.188 & 177.700 & 158.754 & 171.000 & 179.206 \\
Área total $^{\text {Área em uso }}$ & 364.854 & 374.925 & 353.611 & 329.941 & - & - \\
Fronteira legal*** & 228.620 & 237.303 & 224.891 & 223.098 & 246.629 & 257.166 \\
\hline
\end{tabular}

Nota: A área de matas dos estabelecimentos está disponível até a última data do Censo Agropecuário 2006. Para 2012 e 2024, é utilizada a mesma área de 2006.

* Área total dos estabelecimentos agropecuários inclui estradas, pântanos, construções e outros usos.

** Compreende a soma das áreas de matas plantadas, pastagens e lavouras.

*** Diferença entre as áreas legalmente disponíveis, conforme Embrapa (2014), de $2.543 .981 \mathrm{~km}^{2}$ pelas áreas em uso.

Fonte: IBGE (2015), Censo agropecuário 1970/2006, IBGE (2015b) e Embrapa (2015). Elaboração dos autores. 


\subsection{Crescimento das produtividades agropecuárias e realocação produtiva para acomodar as novas demandas por alimentos}

A produtividade da agropecuária brasileira apresentou crescimento contínuo e acentuado após a década de 1970, período no qual se observou um intenso aperfeiçoamento das técnicas de produção. A Tabela 4 apresenta os níveis de produtividade entre 1970 e 2012. Para Muller e Martine (1997), esse aumento da produtividade agropecuária no Brasil esteve muito relacionado ao progresso técnico científico. Para Miranda (2002), isso também foi possível pelo desenvolvimento de variedades de sementes perfeitamente adaptadas às condições de uma agricultura que opera em clima tropical, além das linhas de financiamento, o que proporcionou o aumento da produtividade agropecuária.

Entre os produtos da lavoura, destaca-se a evolução da produtividade do milho e do algodão que mais que quadruplicou no período. As produtividades de soja, arroz e café mais que triplicaram no mesmo período. A bovinocultura brasileira, basicamente de exploração extensiva, apresentou crescimento de $141 \%$ nos 42 anos avaliados. Isso foi acompanhado pelo crescimento de aproximadamente $11 \%$ na área no mesmo período. Já para a silvicultura, o crescimento da produtividade foi acompanhado pela expansão de 28,51\% na área de florestas plantadas entre 2006 e 2012, içados pelas demandas crescentes de celulose e papel (SNIF, 2015).

Embora a produtividade agropecuária brasileira tenha apresentado crescimento acelerado e continuo ao longo dos anos, seu aumento não foi homogêneo criando grandes diferenças entre as regiões brasileiras. A Tabela 5 apresenta as produtividades agropecuárias em 1990 e 2012, por macrorregião do Brasil. Pode-se observar que, em quase todos os produtos avaliados, há significativas diferenças regionais de produtividade.

Entre as lavouras, a soja é o produto com maior extensão de terra, com produtividade média de 2,6 toneladas/ha em 2012. Visualiza-se regionalmente produtividade acima de 3,0 t/ha na região Centro-Oeste, maior produtora nacional, e também de 2,0 t/ha na região Sul. Em 1990, essas diferenças eram menores, com destaque para a baixa produtividade no Nordeste, região que também apresentou elevado crescimento da produtividade nessas três décadas. No caso do milho, as principais regiões produtoras apresentaram produ-

Tabela 4. Evolução da produtividade das terras no Brasil entre 1970 e 2012 (ton/ha)

\begin{tabular}{|c|c|c|c|c|c|c|}
\hline Produtos & 1970 & 1980 & 1985 & 1995 & 2006 & 2012 \\
\hline Arroz & 1,22 & 1,42 & 1,74 & 2,71 & 4,01 & 4,79 \\
\hline Trigo & 0,93 & 0,91 & 1,52 & 1,70 & 1,72 & 2,31 \\
\hline Milho & 1,20 & 1,52 & 1,48 & 2,44 & 3,57 & 5,01 \\
\hline Algodão herbáceo & 0,85 & 1,12 & 1,06 & 1,33 & 2,90 & 3,60 \\
\hline Cana-de-açúcar & 39,97 & 53,62 & 60,53 & 62,09 & 71,71 & 74,30 \\
\hline Soja & 0,86 & 1,64 & 1,77 & 2,33 & 2,58 & 2,64 \\
\hline Feijão & 0,37 & 0,40 & 0,38 & 0,51 & 0,73 & 1,03 \\
\hline Mandioca & 8,44 & 9,53 & 7,60 & 7,49 & 6,97 & 13,61 \\
\hline Outros produtos (L.T) & - & - & - & 4,38 & 7,17 & 13,37 \\
\hline Laranja & 14,86 & 17,19 & 18,72 & 16,51 & 20,40 & 24,99 \\
\hline Café & 0,46 & 0,57 & 0,93 & 1,03 & 1,44 & 1,42 \\
\hline Coco-da-baía & - & - & - & 3,99 & 6,85 & 7,48 \\
\hline Banana & - & - & - & 1,10 & 13,79 & 14,21 \\
\hline Dendê & - & - & - & 10,01 & 12,51 & 11,48 \\
\hline Outros produtos (L.P) & - & - & - & 42,18 & 10,19 & 11,14 \\
\hline Bovinocultura* & 0,51 & 0,68 & 0,71 & 0,86 & 1,11 & 1,23 \\
\hline Produtos da silvicultura** & - & - & - & 22,16 & 25,85 & 27,26 \\
\hline Produtos do fumo & - & 1,23 & 1,48 & 1,51 & 1,95 & 1,98 \\
\hline
\end{tabular}

* Obtidos com a razão da efetividade do rebanho de bovinos, pela área de pastagem.

** Razão entre produção madeireira em tora e lenha pela área plantada, dados disponíveis a partir de 1990.

Fonte: IBGE (2015), IBGE (2015b), Santos et al. (2012). 
Tabela 5. Produtividades agropecuárias regionais no Brasil entre 1990 e 2012 ( $\mathrm{t} /$ hectare)

\begin{tabular}{|c|c|c|c|c|c|c|c|c|c|c|c|c|}
\hline \multirow{2}{*}{ Produtos } & \multicolumn{2}{|c|}{ Brasil } & \multicolumn{2}{|c|}{ Norte } & \multicolumn{2}{|c|}{ Nordeste } & \multicolumn{2}{|c|}{ Sudeste } & \multicolumn{2}{|c|}{ Sul } & \multicolumn{2}{|c|}{ Centro-Oeste } \\
\hline & 1990 & 2012 & 1990 & 2012 & 1990 & 2012 & 1990 & 2012 & 1990 & 2012 & 1990 & 2012 \\
\hline Arroz & 1,9 & 4,8 & 1,4 & 2,8 & 0,8 & 1,2 & 1,5 & 3,2 & 4,0 & 7,3 & 1,2 & 3,4 \\
\hline Trigo & 1,2 & 2,3 & 0,0 & 0,0 & 0,0 & 0,0 & 1,1 & 3,1 & 1,2 & 2,3 & 1,1 & 2,8 \\
\hline Milho & 1,9 & 5,0 & 1,4 & 3,1 & 0,3 & 2,2 & 1,9 & 5,8 & 2,5 & 5,0 & 2,2 & 5,9 \\
\hline Algodão herbáceo & 1,3 & 3,6 & 0,8 & 3,0 & 0,5 & 3,2 & 1,3 & 3,3 & 1,7 & 1,5 & 1,5 & 3,8 \\
\hline Cana-de-açúcar & 61,5 & 74,3 & 49,8 & 63,6 & 48,5 & 56,5 & 68,9 & 78,4 & 65,9 & 70,9 & 65,4 & 73,6 \\
\hline Soja & 1,7 & 2,6 & 1,4 & 3,1 & 0,6 & 2,9 & 1,5 & 2,9 & 1,9 & 2,0 & 1,7 & 3,0 \\
\hline Feijão & 0,5 & 1,0 & 0,6 & 0,8 & 0,3 & 0,2 & 0,6 & 1,6 & 0,6 & 1,4 & 0,6 & 1,8 \\
\hline Mandioca & 12,6 & 13,6 & 13,1 & 15,2 & 10,7 & 8,4 & 14,6 & 18,2 & 17,5 & 20,9 & 15,6 & 17,6 \\
\hline Outros produtos (L.T) & 7,8 & 13,4 & 13,1 & 15,2 & 10,7 & 8,4 & 14,6 & 18,2 & 17,5 & 20,9 & 15,6 & 17,6 \\
\hline Laranja & 96,0 & 25,0 & 91,9 & 16,0 & 89,8 & 13,5 & 97,1 & 28,5 & 88,3 & 23,9 & 69,0 & 19,0 \\
\hline Café em grão & 1,0 & 1,4 & 1,4 & 0,8 & 0,8 & 0,9 & 1,0 & 1,5 & 0,7 & 1,5 & 1,1 & 1,0 \\
\hline Coco-da-baía & 3,4 & 7,6 & 7,8 & 9,8 & 3,1 & 6,4 & 4,2 & 15,8 & - & 10,1 & 7,0 & 13,0 \\
\hline Banana & 1,1 & 14,3 & 1,1 & 12,0 & 1,2 & 12,1 & 1,1 & 16,3 & 1,4 & 20,2 & 0,8 & 13,8 \\
\hline Dendê & 7,4 & 11,0 & 11,0 & 19,0 & 4,2 & 3,8 & - & - & - & - & - & - \\
\hline Outros produtos (L.P) & 43,5 & 11,1 & 48,4 & 6,2 & 40,4 & 10,1 & 65,0 & 15,5 & 43,7 & 10,3 & 26,5 & 10,8 \\
\hline Bovinocultura* & 0,9 & 1,2 & 0,7 & 1,5 & 0,7 & 0,9 & 1,0 & 1,3 & 1,3 & 1,6 & 0,8 & 1,1 \\
\hline Silvicultura & 25,9 & 27,3 & - & 13,8 & - & 23,2 & - & 19,2 & - & 47,0 & - & 14,5 \\
\hline Produtos do fumo & 1,6 & 2,0 & 0,6 & 1,0 & 1,0 & 1,0 & 0,6 & 0,8 & 1,8 & 2,0 & 1,0 & 0,8 \\
\hline
\end{tabular}

* Bovinocultura 1996-2012 - Animais por hectare.

Fonte: Elaboração própria, com base nos dados brutos da produção das lavouras, IBGE (2015b), Poll et al. (2012), Santos et al. (2013), IBGE (2015).

tividade similar, próxima de 6,0 t/ha em 2012, enquanto a região Nordeste apresentou apenas 2,2 t/ha. Os ganhos de produtividade para o milho e o algodão nesse período foram mais significativos entre as lavouras. Segundo Carvalho et al. (1988) e Heinze (2002), o desenvolvimento da agropecuária no Nordeste brasileiro foi possível por meio da implantação de tecnologias de irrigação.

No que se refere à bovinocultura, o número de animais por área no Brasil é considerado muito baixo diante das potencialidades, uma vez que pode ocorrer o confinamento dos animais. Na Tabela 5 verifica-se lotação média de 1,2 animal por hectare em 2012. Embora tenha ocorrido aumento nesse indicador nas três décadas observadas, as diferenças regionais ainda são pequenas, com destaque para a região Sul, que apresenta 1,6 cabeça/ha. A elevada disponibilidade de áreas e o baixo custo de oportunidade da terra para a criação animal contribuiu para a adoção de um sistema extensivo utilizado no Brasil.

Novas melhorias no sistema produtivo, usando técnicas bem difundidas, como a integração lavoura-pecuária e a recuperação de pasto, podem rapidamente elevar a lotação. Segundo Vilela e Pulrolnik (2015), a taxa de lotação projetada para o sistema de integração lavoura-pecuária é duas cabeças por hectare. Isso representaria a liberação de grandes áreas de terras para a produção de cultivos.

A produtividade agropecuária no Brasil é heterogênea na maioria dos produtos, assim como seu crescimento. De forma geral, alguns estabelecimentos no País apresentam produtividades muito abaixo da média nacional. Isso está relacionado, em alguns casos, aos ganhos de escala e à baixa remuneração sobre os estabelecimentos. Segundo Bresser-Pereira (1964), os estabelecimentos agropecuários brasileiros sofrem com a baixa remuneração do trabalho, não possibilitando aumentar as taxas de capital nas lavouras. Buainain et al. (2003) destacam ainda que, em praticamente todas as regiões, os agricultores enfrentam problemas associados à disponibilidade de capital de giro e recursos para investimentos, o que dificulta o crescimento da produtividade dos estabelecimentos.

Além dos fatores microeconômicos, os diferentes climas regionais definem as diferenças de produtividade observadas. Porém, regiões como Norte e Nordeste, que apresentaram elevada defasagem em relação à produtividade, de forma geral, vêm apresentando uma tendência de aproximação da média das grandes regiões produtoras. Isso se deve, em 
grande parte, aos investimentos realizados na região, o que proporcionou melhorias nas técnicas de cultivo, uso de híbridos e implantação de tecnologia de irrigação (MIRANDA, 2002; BUAINAIN et al., 2003; CRISÓSTOMO et al., 2003). Em análise do tema para o período de 1991 e 2003, Almeida et al. (2008) encontraram evidências em favor da existência de convergência absoluta da produtividade agrícola das microrregiões brasileiras. Isso sugere que a produtividade agrícola brasileira estaria convergindo para a média; porém, a uma taxa muito lenta. Essa convergência também foi constatada em pesquisa de Helfand, Maralhães e Rada (2015), em que os autores observam uma expansão significativa dos investimentos em tecnologias intermediárias e capital nos pequenos estabelecimentos agropecuários do Norte e Nordeste, entre 1985 e 2006.

Além do aumento da produtividade das principais lavouras e da bovinocultura no Brasil, as mudanças no uso da terra passam a representar outro importante caminho para ampliar a produção de alimentos. Em estudo realizado em Mato Grosso do Sul, entre 2010 e 2014, verificou-se que o crescimento de quase um milhão de hectares com cultivos estava predominantemente sobre áreas antes de pastagem (BUNGENSTAB,
2015). A necessidade de aperfeiçoar áreas em uso tem levado à substituição de atividades, especialmente ocupando áreas de pastagem. A menor possibilidade de expansão das fronteiras agrícolas e o aumento dos custos de oportunidade da terra devem pressionar ainda mais a necessidade de maior produtividade das atividades agropecuárias no Brasil nos próximos anos.

Considerando-se esses possíveis ajustes de produtividade, a Tabela 6 apresenta os resultados, em termos de produtividade, necessários em 2024 para atender à demanda estimada. Além disso, são expostas as produtividades do fator terra necessárias, incluindo o uso total das áreas ainda disponíveis legalmente, conforme indicado pelo estudo da Embrapa. Esse limite seria de 254,4 milhões de hectares para as atividades agropecuárias no Brasil.

Na coluna 2 e 3 da Tabela 6 visualizam-se ganhos de produtividade esperados no período e, na coluna 4, o resultado desse crescimento sobre as áreas de terra demandadas para a produção agropecuária. Em quase todos os produtos são verificadas projeções de aumento de produtividade, embora muito abaixo do que observado nas últimas décadas. No caso da pecuária, a projeção indica crescimento de quase $30 \%$ na alo-

Tabela 6. Crescimento da produtividade, da produção agropecuária e da demanda de novas áreas de terra entre 2012 e 2024

\begin{tabular}{lcccc}
\hline \multicolumn{1}{c}{ Produtos } & $\begin{array}{c}\text { Produtividade em 2012 } \\
\text { (t/ha) }\end{array}$ & $\begin{array}{c}\text { Produtividade } \\
\text { projetada para 2024* }\end{array}$ & $\begin{array}{c}\text { Demanda projetada } \\
\text { de terras em 2024 }\end{array}$ & $\begin{array}{c}\text { Produt. necessária em } \\
\text { 2024 consid. os limites } \\
\text { legais de terra }\end{array}$ \\
\hline Arroz & 4,79 & 5,50 & 2.155 & 4,84 \\
Trigo & 2,31 & 3,03 & 1.502 & 2,34 \\
Milho & 5,01 & 5,39 & 14.572 & 5,06 \\
Algodão herbáceo & 3,60 & 5,53 & 1.106 & 3,64 \\
Cana-de-açúcar & 74,30 & 81,33 & 9.361 & 75,11 \\
Soja em grão & 2,64 & 3,00 & 22.637 & 2,67 \\
Feijão & 1,03 & 1,22 & 2.709 & 1,04 \\
Mandioca & 13,61 & 15,14 & 1.597 & 13,76 \\
Outros produtos (LT) & 13,37 & 13,37 & 1.948 & 13,51 \\
Laranja & 24,99 & 25,30 & 738 & 25,26 \\
Café em grão & 1,42 & 1,76 & 1.710 & 1,44 \\
Coco-da-baía & 7,48 & 7,48 & 260 & 7,57 \\
Banana & 14,21 & 18,36 & 375 & 14,36 \\
Dendê & 11,48 & 11,48 & 114 & 11,60 \\
Outros produtos (LP) & 11,14 & 11,14 & 2.423 & 11,26 \\
Bovinos & 1,23 & 1,60 & 138.387 & 1,25 \\
Produtos da silvicultura & 27,26 & 27,26 & 6.545 & 27,55 \\
Produtos do fumo & 1,98 & 2,24 & 449 & 2,00 \\
Áreas de terras & 246.629 & - & 208.586 & 254.398 \\
\hline
\end{tabular}

Fonte: * Produtividades projetadas obtidas dos seguintes trabalhos: Mapa (2012), Mapa (2014), Fiesp (2014), Embrapa (2014), IBGE (2015b) e Carvalho et al. (2010). Cálculos realizados pelos autores. 
cação animal por hectare, o que levaria à ocupação de 138,4 milhões de hectares e uma liberação de quase 33 milhões de hectares para outras atividades.

Mesmo para as lavouras de soja, cana-de-açúcar e milho, que atualmente apresentam uso de grandes áreas de terra no Brasil, o aumento das produtividades projetadas é suficiente para liberar áreas hoje ocupadas. Somente a cultura do algodão teria ampliação significativa de área para a produção em 2024 comparada com a utilizada em 2012. Considerando-se todas as atividades da Tabela 6, a área de ocupação projetada para 2024 é de 208,6 milhões de hectares, o que está dentro dos limites legais, de 254,4 milhões de hectares.

Na coluna 5 da Tabela 6 são apresentadas as produtividades necessárias por atividade em 2024 para garantir que os limites legais sejam respeitados; ou seja, a produtividade necessária para equilibrar a oferta de terras no Brasil e a demanda mundial de alimentos por produtos brasileiros. Os números indicam a necessidade de pequenos ajustes na produtividade para que o crescimento da produção atenda às demandas nacionais e internacionais de alimentos e derivados de floresta nacionais, respeitando o limite legal. A ampliação da produtividade estimada deve exigir um crescimento médio de 1,17\% a 2,28\% ao ano para: soja, milho, cana-de-açúcar, arroz e trigo.

O conjunto de informações apresentadas neste tópico permite visualizar que pequenos ajustes de produtividade são suficientes para acomodar a crescente demanda de alimentos de forma a respeitar os limites legais nos próximos anos, ou seja, de sustentabilidade. Esses ajustes deverão ser acompanhados pela realocação de muitas culturas, especialmente sobre as áreas de pecuária. A grande heterogeneidade observada entre as regiões e estabelecimentos agropecuários em todo o Brasil também é importante fonte de possíveis ganhos de produtividade média da terra nos próximos anos.
Cabe observar que, entre os fatores que permitem ampliar a produtividade, estão os ganhos de escala, o uso de tecnologias, ampliação do capital produtivo e qualificação da mão de obra, conforme destacam Helfand et al. (2015). Um dos grandes desafios no esforço de ampliação da produtividade é a necessidade de investimentos nas atividades produtivas.

\subsection{Desafios para o crescimento da produtividade e políticas econômicas para a próxima década}

Uma vez apresentados os ajustes necessários da produtividade brasileira e os limites da fronteira agropecuária, são expostos a seguir os principais desafios para aumentar a produtividade. Segundo Lal (2004), o crescimento da produtividade agropecuária pode ocorrer com a correção dos solos e irrigação eficiente. Rocha et al. (2015) argumentam que as áreas irrigadas promovem aumento substancial da produtividade e redução dos preços dos alimentos. Nesse sentido, na Tabela 7 são apresentas as áreas efetivamente irrigadas nas regiões brasileiras em 2006. Observa-se que apenas 7,51\% das áreas de lavouras são efetivamente irrigadas no Brasil, com taxa mais alta para a região Sudeste, onde $12,04 \%$ das lavouras são irrigadas. A região Nordeste compreende $6,64 \%$ da área de lavouras irrigadas, sendo que os estabelecimentos de 0 a 5 hectares têm maior percentual de áreas de lavouras irrigadas, $10,42 \%$.

O potencial de irrigação das lavouras brasileiras está sujeito à disponibilidade de recursos híbridos. No Nordeste brasileiro, região que sofre com a escassez de chuvas, conforme Suassuna (2014), são passíveis de irrigação cerca de 2,2 a 2,5 milhões de hectares. A viabilidade da irrigação no Nordeste brasileiro torna-se problemática, pois, além da alta salinidade dos poços, a região enfrenta a baixa remuneração da mão de obra,

Tabela 7. Percentual da área de lavouras (permanente mais temporária) irrigada em 2006, discriminados por tamanho da área dos estabelecimentos (em \%)

\begin{tabular}{lcccccc}
\hline \multicolumn{1}{c}{ Regióes } & Total & $\begin{array}{c}\text { Maior de } \mathbf{0} \\
\text { a menos de } \mathbf{5} \text { ha }\end{array}$ & $\begin{array}{c}\text { De } \mathbf{5} \text { a menos } \\
\text { de } \mathbf{2 0} \text { ha }\end{array}$ & $\begin{array}{c}\text { De } \mathbf{2 0} \text { a menos } \\
\text { de } \mathbf{1 0 0} \text { ha }\end{array}$ & $\begin{array}{c}\text { De 100 a menos } \\
\text { de } \mathbf{5 0 0} \text { ha }\end{array}$ & $\begin{array}{c}\text { Mais de } \\
\mathbf{5 0 0} \text { ha }\end{array}$ \\
\hline Brasil & 7,51 & 13,86 & 7,77 & 5,11 & 7,29 & 7,43 \\
Norte & 2,59 & 10,84 & 5,57 & 1,46 & 1,57 & 2,70 \\
Nordeste & 6,64 & 10,42 & 7,32 & 3,60 & 5,08 & 7,24 \\
Sudeste & 12,04 & 33,39 & 17,26 & 8,96 & 8,65 & 11,64 \\
Sul & 8,16 & 8,34 & 3,86 & 4,92 & 10,24 & 11,39 \\
Centro-Oeste & 4,64 & 52,38 & 14,19 & 5,25 & 4,83 & 4,21 \\
\hline
\end{tabular}

Fonte: Dados brutos IBGE (2015). Censo agropecuário 2006. Tabela e cálculos elaborados pelos autores. 
a baixa escolaridade e é castigada pela irregularidade das chuvas, o que dificulta a criação de sistemas de armazenagem de água. Essa problemática faz necessários investimentos na área de planejamento híbrido na região, com políticas mais eficientes voltadas para irrigação eficiente e que minimizem os desperdícios. Segundo a ONU (2015b), até 2030, o planeta enfrentará um déficit de água de $40 \%$, a menos que a gestão deste recurso seja melhorada dramaticamente.

Mediante a necessidade de ampliar a irrigação sustentável, o governo brasileiro vem realizando políticas de irrigação. Rocha et al. (2015) salientam que o Mapa definiu que as áreas prioritárias para irrigação são as adotadas para atuar em cooperação e as decorrentes das responsabilidades relacionadas com a necessidade de compatibilizar as políticas de recursos híbridos ao meio ambiente. Portanto, no exercício das atribuições do Mapa foram definidos dois objetivos, a saber:

- Objetivo 0163 - Aperfeiçoar as políticas creditícia e securitária voltadas à irrigação com vistas a ampliar a área irrigada, aumentar a produtividade e a qualidade dos produtos e contribuir para a contenção do avanço da fronteira agrícola.

- Objetivo 0171 - Promover e fortalecer a pesquisa, o desenvolvimento tecnológico e a inovação voltados para a agricultura irrigada e a sua difusão, visando o incremento nos ganhos em produtividade, com qualidade e redução dos custos de produção.

As atribuições do Mapa, junto à disponibilidade do crédito agrícola, podem viabilizar o processo de irrigação no semiárido brasileiro, aumentando a produtividade agropecuária. Para Rebouças et al. (1997), a transposição do rio São Francisco viabiliza a irrigação do semiárido brasileiro, mas é necessário o uso sus- tentável do recurso, pois a ONU (2015b) alerta que os recursos hídricos são renováveis, mas as quantidades disponíveis em qualquer tempo ou lugar refletirão os limites do seu ciclo natural.

Além do processo de irrigação, a melhora da adubação é fundamental para o crescimento da produtividade. Segundo a FAO (2013), o crescimento da oferta mundial de alimentos nas últimas décadas só foi possível pelas práticas de irrigação, uso de adubos e conservação dos solos. No Brasil, conforme indicado Tabela 8, apenas $27,27 \%$ dos 5,17 milhões de estabelecimentos agropecuários utilizavam adubos nas lavouras em 2006. O uso de adubos em pastagens é ainda menor, de $1,63 \%$. O desafio para a utilização de adubos químicos na agricultura brasileira está no aumento dos preços dos insumos devido à redução dos estoques da matéria-prima, como destaca Cordell (2009).

Além do uso de fertilizantes e irrigação para proporcionar o aumento da produtividade agropecuária, a especialização dos estabelecimentos também se apresenta como forma viável para ampliar a produção. Segundo Guanziroli (2007), na agricultura familiar brasileira apenas $11,5 \%$ de seus estabelecimentos apresentam produção muito especializada, em que um único produto atinge $100 \%$ do valor bruto de sua produção. $\mathrm{O}$ sistema mais frequente é o diversificado, com 41,1\% dos estabelecimentos tendo um único produto atingido de $35 \%$ a $65 \%$ do VBP. Os agricultores familiares especializados, representados por $29,4 \%$ do total são, entretanto, os que obtêm a maior renda total, tanto por estabelecimento quanto por unidade de área, sendo $\mathrm{R} \$ 3.885$ por estabelecimento ao ano e R $\$ 139$ por hectare. Os agricultores muito especializados apresentavam a maior renda média por estabelecimento, de R\$4.604.77, em 2006.

Conforme evidências encontradas em Guanziroli (2007), a maior especialização da agricultura familiar

Tabela 8. Percentual dos estabelecimentos que utilizam adubos nas lavouras e pastagens em 2006 (em \%)

\begin{tabular}{lcc}
\hline \multicolumn{1}{c}{ Regiões } & $\begin{array}{c}\text { Usam adubos em lavouras } \\
(\boldsymbol{\%})\end{array}$ & $\begin{array}{c}\text { Usam adubos em pastagens } \\
(\boldsymbol{\%})\end{array}$ \\
\hline Brasil & 27,27 & 1,63 \\
Norte & 8,44 & 0,47 \\
Nordeste & 15,90 & 0,90 \\
Sudeste & 43,17 & 2,79 \\
Sul & 52,50 & 2,36 \\
Centro-Oeste & 17,22 & 3,37 \\
\hline
\end{tabular}

Fonte: Dados brutos IBGE (2015). Censo agropecuário 2006. Tabela e cálculos elaborados pelos autores. 
pode contribuir para o crescimento da produtividade agrícola. Enquanto os agricultores com grandes extensões de terras proporcionariam produtos que visam ganho de escala, a agricultura familiar se especializaria em culturas com menores ganhos de escala e/ou que proporcionam rentabilidade e perpetuação da unidade produtiva.

Outro caminho para os ajustes de produção é a troca de pastagens naturais por pastagens plantadas, que proporcionariam maior lotação do rebanho brasileiro por hectare. O melhoramento das pastagens, além de aumentar a lotação, possibilita a expansão das lavouras brasileiras sobre a área da pecuária. Esse processo já foi estudado anteriormente e constitui um movimento com resultados positivos para o aumento da produção agropecuária, como destacam Torres et al. (2004).

Em conformidade, segundo Brandão et al. (2006), a conversão de pastagens degradadas é um mecanismo por meio do qual a pecuária pode conseguir renovar suas pastagens. A implementação desses métodos elevaria a capacidade de lotação da pecuária, disponibilizando novas terras para a expansão das lavouras brasileiras. Conforme comentam Carvalho et al. (2014), a limitação na oferta de terras brasileiras pressupõe que as áreas de pastagens terão redução primeiro, seguidas de trocas de culturas entre as lavouras, definidas pelos preços das commodities.

O processo de melhoria das técnicas de produção deve ocorrer com conhecimento técnico e uso da agricultura de precisão, a qual já foi abordada na revisão de literatura deste trabalho. Embora as técnicas para o aumento da produtividade existam, um dos principais empecilhos à implantação é a baixa remuneração dos estabelecimentos agropecuários, principalmente nos de menor porte, que não conseguem obter financiamentos no sistema financeiro comercial, como destaca Kageyama (2003).

Para anemizar esse problema, o governo brasileiro utiliza-se do crédito subsidiado. Kageyama (2003) explica que o crédito subsidiado proporciona grandes gastos ao governo brasileiro. Além disso, conforme Kageyama (2003), os programas de financiamento deveriam dar atenção especial ao risco de contribuir para difundir o "pacote tecnológico produtivista", sem um controle associado dos possíveis danos ambientais que podem resultar do uso intensivo de 78 agroquímicos. Portanto, os programas devem ir além do simples financiamento de práticas produtivas moder- nas, mas devem contribuir para introduzir mudanças nos sistemas produtivos no sentido de diminuir a sua dependência de insumos externos, bem como utilizar práticas que sejam ambientalmente mais adequadas a cada situação e que respeitem a cultura tecnológica dos agricultores.

Ainda que o governo brasileiro venha desenvolvendo políticas de incentivo à agricultura, tanto de acesso ao crédito quanto de aplicação de políticas macroeconômicas, como ressalta Kageyama (2003), os incentivos ao crédito ainda são deficitários no âmbito de financiar os melhores projetos e ao acesso ao mesmo. Os gastos do governo e a eficiência dos investimentos podem ser potencializados ao financiar os projetos mais rentáveis e necessários para aumentar a produtividade agrícola.

Além dos problemas de acesso ao crédito, a problemática das mudanças climáticas dificulta o crescimento da produtividade, como argumenta Abramovay (2010). Mediante essa problemática, as políticas de crescimento sustentável devem ser mais ativas para garantir a segurança alimentar mundial. As políticas de controle de emissão de efeito estufa, já em vigor pelo protocolo de Kyoto, têm como objetivo a redução da emissão dos gases causadores do efeito estufa, o que pode ajudar na redução dos efeitos do aquecimento global sobre a produtividade. Assim, a implementação do protocolo e controles sobre o uso de defensivos agrícolas devem ser mais eficazes, buscando um crescimento sustentável em longo prazo.

Por fim, o crescimento da produtividade e a existência de uma agropecuária sustentável de longo prazo não dependem somente da ciência. É necessário que os governos e as instituições criem um ambiente propício ao desenvolvimento e à difusão das soluções.

\section{Conclusões}

O crescimento populacional, a maior concentração da população nas cidades e o aumento da renda per capita nas próximas décadas devem sustentar um contínuo crescimento da demanda mundial de alimentos. No passado, o aumento acelerado da produtividade, junto à expansão da fronteira agrícola, deram conta de evitar a falta generalizada de alimentos. Mais recentemente, o crescimento das áreas agropecuárias teve intensa desaceleração e os limites estão muito 
próximos. Além disso, aumentos de produtividade como observados no passado não devem se repetir; podendo ainda ser reduzidos por problemas relacionados ao clima. Isso acrescenta mais um desafio na garantia da segurança alimentar da população mundial.

Nesse debate, o Brasil se apresenta como um dos poucos países com grande potencial produtivo. Para analisar como as novas demandas devem pressionar as fronteiras agropecuárias no Brasil até 2024, o presente trabalho investigou a disponibilidade de novas áreas de terras e os ajustes de produtividade necessários para atender às demandas projetadas.

Utilizando os limites legais para o uso das terras agropecuárias estimado pela Embrapa (2014), constatou-se que, em 2012, restavam no Brasil 7,8 milhões de hectares possíveis de exploração, o que representava cerca de $3 \%$ da área utilizada naquele ano. Essa disponibilidade de novas áreas não é suficiente para atender às novas demandas mundiais de alimentos por produtos brasileiros até 2024, mantidas as produtividades de 2012. Assim, não é possível rejeitar a hipótese de que, para o Brasil atender às demandas por produtos agropecuários até 2024, é necessária a expansão da produtividade e da área plantada. Outro importante resultado é o de que pequenos ajustes de produtividade, especialmente na pecuária, são suficientes para atender às novas demandas, sem ampliação de área. As diferenças de produtividade regionais também indicam que investimentos produtivos podem elevar a produtividade em muitas regiões, ampliando ainda mais a capacidade de produção de alimentos no Brasil para a próxima década.

Assim, a oferta de alimentos projetada em território brasileiro para os próximos anos não deve ser prejudica pela ausência de novas áreas de terras, garantindo, assim, a segurança alimentar no que se refere à oferta de alimentos. Os riscos de menor oferta de alimentos no Brasil estão mais diretamente relacionados aos problemas climáticos. Embora o crescimento de lavouras e pecuária nas últimas décadas tenha ocorrido também sobre áreas de floresta, especialmente na região Amazônica, os dados apresentados demonstram que isso pode ser superado sem prejuízo da oferta de alimentos.

Por fim, cabe reconhecer que o método adotado de insumo-produto não permite a substituição entre insumos e entre culturas. Embora essa possibilidade tenha sido analisada, o modelo utilizado não a considera. $\mathrm{O}$ uso de modelos de equilíbrio geral pode supe- rar essa restrição. Os trabalhos de Ferreira Filho et al. (2015) e Carvalho e Domingues (2014) utilizaram essa abordagem metodológica, mas o problema estudado foi a relação entre desmatamento da Amazônia e uso da terra. Portanto, futuros trabalhos utilizando modelos de equilíbrio geral para analisar o crescimento da demanda mundial de alimentos e o uso da terra no Brasil devem ser explorados.

\section{Referências}

ABRAMOVAY, R. Alimentos versus população: está ressurgindo o fantasma malthusiano? Ciência e Cultura, v. 62 , n. 4 , p. 38-42, 2010.

ALMEIDA, E. S., PEROBELLI, F. S. e FERREIRA, P. G. C. Existe convergência espacial da produtividade agrícola no Brasil? Revista de Economia e Sociologia Rural, v. 46, n. 1, p. 31-52, 2008.

BRANDÃO, A. S. P., REZENDE, G. C. e MARQUES, R. W. C. Crescimento agrícola no período 1999/2004: a explosão da soja e da pecuária bovina e seu impacto sobre o meio ambiente. Economia Aplicada, v. 10, n. 2, p. 249-266, 2006.

BRASIL. Ministério da agricultura. Home. Disponível em último acesso, mar. 2015.

BRESSER-PEREIRA, L. C. Problemas da agricultura brasileira e suas causas. Journal of Inter-American Studies, v. 6, n. 1, p. 43-55, jan. 1964.

BUAINAIN, A. M. Agricultura familiar e o novo mundo rural. Sociologias, v. 5, n. 10, 2003.

BULMER-THOMAS, V. Input-output analysis in developing countries: source, methods and applications. New York: Wiley, 1982.

BUNGENSTAB. D. J. Mudanças do uso da terra como oportunidade. Revista Opiniões, A introdução da lavourapecuária-floresta, 2015. ISSN: 2177-6504.

CARVAlHO, O. A economia política do Nordeste: secas, irrigação e desenvolvimento. Rio de Janeiro: Campus, 1988.

CARVALHO, T. B. e FURLANETTO, L. E. Z. S. E. R. G. Potencial da produtividade e rentabilidade da pecuária de corte no mato grosso. Congresso, n. 48, Sober, 25 a 28 de jul. 2010. Campo Grande-MS, 2010.

CARVALHO, T. S. e DOMINGUES, E. P. Impactos econômicos e de uso do solo de uma politica de controle de desmatamento na Amazônia Legal brasileira. $42^{\underline{o}}$ 
Encontro nacional de economia - ANPEC, Natal-RN, 9-12 dez. 2014.

CEPII. The world economy in 2050: a tentative picture, CEPII Working paper, 2010-27, 2010.

CORDELL, D., DRANGERT, J-O. e WHITE, S. The story of phosphorus: global food security and food for thought. Global Environmental Change, v. 19, n. 2, p. 292305, 2009.

- et al. Towards global phosphorus security: a systems framework for phosphorus recovery and reuse options. Chemosphere, v. 84, n. 6, p. 747-758, 2011.

CRISÓSTOMO, L. A. et al. Adubação, irrigação, híbridos e práticas culturais para o meloeiro no Nordeste. Embrapa Agroindústria Tropical. Circular Técnica, 2003.

DA SILVEIRA, F. G. e DE ALMEIDA, M. E. K. Fome, produção alimentar e distribuição de renda. Indicadores Econômicos FEE, v. 19, n. 4, p. 151-166, 1992.

DAUBERMANN, E. C. et al. Expansão da área agrícola e produtividade das culturas no Brasil: testando hipóteses da legislação californiana de biocombustíveis. Revista de Economia e Sociologia Rural, v. 52, n. 1, p. 81-98, 2014.

DE LIMA FILHO, R. R., AGUIAR, G. A. M. e JUNIOR, A. M. T. Mapitoba-A última fronteira agrícola. AgroANALYSIS, v. 33, n. 05, p. 15-16, 2013.

DOBBS, R. et al. Resource revolution: meeting the world's energy, materials, food, and water needs. McKinsey \& Company, nov. 2011.

EMBRAPA. Embrapa monitoramento por satélite. Resumo. Disponível em: <http://www.alcance.cnpm. embrapa.br>. Acesso em: dez. 2014.

FALCON, W. P. e NAYLOR, R. L. Rethinking food security for the twenty-first century. American Journal of Agricultural Economics, v. 87, n. 5, p. 1113-1127, 2005.

FAO. How to feed the world in 2050. High level expert forum. Convened at FAO Headquarters in Rome on 12-13 October, 2009.

. Fao statistical yearbook 2013 world food and agriculture. Food and Agriculture Organization of the United Nations, Rome p. 307, 2013.

The state of food insecurity in the world 2014. Food and Agriculture Organization of the United Nations. Home. Disponível em: < http://www.fao.org/ publications/sofi/en/> . Acesso em: jul. 2015.

FERRARI, R. A. e SCABIO, V. S. O. A. Biodiesel de sojaTaxa de conversão em ésteres etílicos, caracterização físico-químico e consumo em gerador de energia. Revista, Quim. Nova, v. 28, n. 1, p. 19-23, 2005.

FERREIRA FILHO, J. B. S. e MORAES, G. I. Climate change, agriculture and economic effects on different regions of Brazil. Environment and Development Economics, v. 20, n. 1, p. 37-56, 2015.

FERREIRA-FILHO, J. e HORRIDGE, M. Endogenous land use and supply, and food security in Brazil. Victoria University, Centre of Policy Studies/IMPACT Centre, 2012.

FIESP. Projeções para o agronegócio brasileiro. Federação das Indústrias de São Paulo. nOutlook FIESP, 2014.

GUANZIROLI, C. E. PRONAF dez anos depois: resultados e perspectivas para o desenvolvimento rural. Revista de Economia e Sociologia Rural, SOBER, Rio de Janeiro, v. 45, n. 2, p. 301-328, abr.jun. 2007.

GUILHOTO, J. J. M. Análise de insumo-produto: teoria e fundamentos. FEA, Universidade de São Paulo-USP, mar. 2004.

e SESSO FILHO, U. A. Estimação da Matriz Insumo-Produto Utilizando Dados Preliminares das Contas Nacionais: Aplicação e Análise de Indicadores Econômicos para o Brasil em 2005. Economia $\mathcal{E}$ Tecnologia, UFPR/TECPAR, ano 6, v. 23, out./dez. 2010.

HEINZE, B. C. L. B. Importância da agricultura irrigada para o desenvolvimento da Região Nordeste do Brasil. Monografia apresentada ao curso MBA em Gestão Sustentável da Agricultura Irrigada da ECOBUSINESS SCHOOL/FGV. Brasília, 2002.

HELFAND, S., MAGALHÃES, M. e RADA, N. E. Brazil's Agricultural Total Factor Productivity Growth by Farm Size. Agricultural \& Applied Economics Association's 2015 AAEA \& WAEA Joint Annual Meeting, San Francisco-CA, 26-28 jul. 2015.

IBGE. Censos agropecuários 1970, 1980, 1985, 1995 e 2006. Instituto Brasileiro de Geografia e Estatística. Disponível em: < http://www.ibge.gov.br>. Acesso em: jul. 2015.

. Contas Nacionais Trimestrais. Instituto Brasileiro de Geografia e Estatística. Disponível em: <http:// www.ibge.gov.br/home/estatistica/indicadores/pib/ defaultcnt.shtm >. Acesso em: jul. 2015a.

. Banco de Dados Agregados. Sistema IBGE de Recuperação Automática - SIDRA. Instituto Brasileiro de Geografia e Estatística. Disponível em: < http://www. ibge.gov.br>. Acesso em: 22 ago. 2015b.

Banco de Dados Agregados. Sistema IBGE de Recuperação Automática - SIDRA. Produção da Extração Vegetal. Instituto Brasileiro de Geografia $e$ Estatística. Disponível em: <http://www.ibge.gov.br>. Acesso em: 22 ago. 2015c.

. Banco de Dados Agregados. Sistema IBGE de Recuperação Automática - SIDRA. Pesquisa Pecuária Municipal. Instituto Brasileiro de Geografia e Estatística. 
Disponível em: <http://www.ibge.gov.br>. Acesso em: 22 ago. 2015 d.

IFPRI. Climate change. Impacts agriculture and costs of adaptation. Food Policy Report. Washington. IFPRI, 2009. Disponível em: <http://www.ifpri.org/publication/ climate-change-impact-agriculture-and-costsadaptation>. Acesso em: 25 jul. 2015.

INSTITUTE, W. Additional losses and abandonment of agricultural land are caused by water logging, salinization, urbanization and others processes as discussed later in the text. The World Resources Institute. New York: Oxford University Press, 1964.

KAGEYAMA, A. Produtividade e renda na agricultura familiar: efeitos do PRONAF-crédito. Agricultura em São Paulo, v. 50, n. 2, p. 1-13, 2003.

LAL, R. e STEWART, B. A. (Eds.). Soil erosion and land degradation: the global risks. In: Advances in soil science. New York: Springer-Verlag, 1990.

MAPA. Projeções do Agronegócio Brasil 2011-2012 a 2020-2022. Projeções de Longo Prazo. Ministério da Agricultura e Abastecimento. Brasília-DF, 2012.

. Projeções do agronegócio - Brasil 2013/2014 a 2023/24. Projeções de Longo Prazo. Ministério da Agricultura e Abastecimento. Brasília-DF, 2014.

MILLER, E. R. e BLAIR, P. D. Imput-output analysis: foundations and extensions. 2. ed. Englewood Cliffs, New Jersey: Prentice-Hall Inc., 2010.

MIRANDA, E. E. Terras do Brasil: o alcance da legislação ambiental e territorial. Revista ECO-21, Rio de Janeiro-RJ, p. 9, 1 nov. 2008.

et al. $\mathrm{O}$ alcance da legislação ambiental e territorial. Revista Agroanalysis, Fundação Getúlio Vargas, São Paulo-SP, p. 25-31, dez. 2008.

MIRANDA. E. F. Agricultura: 1994/2002 - Crescimento e modernização. Panorama Macroeconômico Brasileiro. Ministério da Fazenda Secretaria de Politica Econômica, ago. 2002.

MULLER, C. C. e MARTINE, G. Modernização da agropecuária, emprego agrícola e êxodo rural no Brasil: a década de 1980. Revista de Economia Política, São Paulo, v. 17, n. 3, p. 67, 1997.

OLIVEIRA, C. G. K. Produtividade de arroz híbrido em função da contaminação genética e densidade de semeadura. Dissertação (Mestrado) - Universidade Federal de Pelotas Faculdade de agronomia "Eliseu Maciel". Pelotas, Rio Grande do Sul, Brasil, 2010.
ONU. United nations, department of economic and social affairs. The United Nations, Population Division, Population Estimates and Projections Section, 2012.

. The United Nations World Water Development Report 2015: Water for a Sustainable World. WWAP (United Nations World Water Assessment Programme). The United Nations, Paris, UNESCO, 2015.

World urbanization prospects: The 2014 revision. The United Nations, Department of Economic and Social Affairs, Population Division, 2014. Highlights (ST/ESA/SER.A/352).

PEREIRA, C. P. A pobreza, suas causas e interpretações: destaque ao caso brasileiro. Revista SER Social, n. 18, p. 229-252, 2010.

PIMENTEL, D. et al. Land degradation: effects on food and energy resources. Science, v. 194, n. 4261, p. 149155, 1976.

POLL, H. et al. Anuário brasileiro da pecuária 2013. Santa Cruz do Sul: Editora Gazeta Santa Cruz, 2013.

REBOUÇAS, A. C. Água na região Nordeste: desperdício e escassez. Estudos Avançados, v. 11, n. 29, p. 127-154, 1997.

ROCHA, C. T. D. e CHRISTOFIDIS, D. Vantagens da opção pela agricultura irrigada. Revista de Politica Agrícola, ano XXIV, n. 2, p. 17-25, abr./jun. 2015.

SANTOS, C. Anuário brasileiro da silvicultura 2012. Santa Cruz do Sul: Editora Gazeta Santa Cruz, 2012.

SAYWER, D. R. Fluxo e refluxo da fronteira agrícola no Brasil: ensaio de interpretação estrutural e espacial. Revista Brasileira de Estudos de População, v. 1, n. 1/2, p. 3-34, 2013.

SNIF - Sistema Nacional de Informação Florestal. Brasília, 2015. Disponível em: <http://www.florestal. gov.br/>. Acesso em: ago. 2015.

SUASSUNA, J. Semi-Árido: proposta de convivência com a seca. Fundação Joaquin Nabuco - desenvolvimento com educação, 2014.

TORRES JR., A. de M., ROSA, F. R. T. e NOGUEIRA, M. P. Mais boi em menos pasto. Agroanalysis, ago. 2004.

VICTORIA, D. de C. et al. Delimitação de áreas de preservação permanente em topos de morro para o território brasileiro. Revista Geográfica Acadêmica, Edição Especial SRTM - Conceitos e Aplicações, v. 2, n. 2, p. 66-72, 2008.

VILELA, L. e PULROLNIK. K. Segurança alimentar e a sustentabilidade. Opiniões, v. 12, n. 40, p. 12-14, jun./ ago. 2015.

Todo o conteúdo deste periódico, exceto onde estiver identificado, está licenciado sob uma Licença Creative Commons (cc by 4.0 ) 